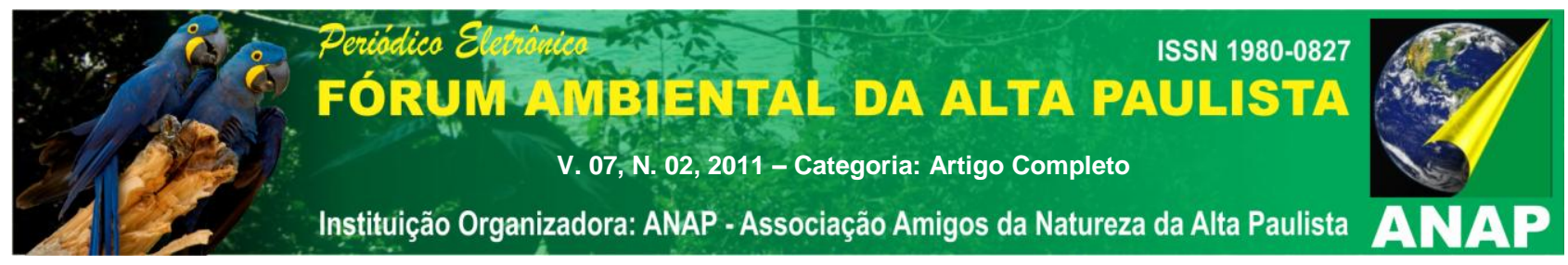

\title{
SIG APLICADO NA IDENTIFICAÇÃO E LOCALIZAÇÃO POTENCIAL DE ÁREAS DE PRESERVAÇÃO PERMANENTE NUMA MICROBACIA
}

\author{
Sérgio Campos ${ }^{1}$
}

Teresa Crisitna Tarlé Pissarra²

Katiuscia Fernandes Moreira ${ }^{3}$

Thaís Maria Millani ${ }^{3}$

\section{Gabriel Rondina Pupo da Silveira ${ }^{3}$}

RESUMO: O uso inadequado do solo é um fator agravante da degradação ambiental e desequilíbrio ecológico. Este trabalho visou avaliar os conflitos de uso da terra em áreas de preservação permanentes (APP) na microbacia do São Pedro - Botucatu (SP) através de Sistema de Informações Geográficas e imagem de satélite de 2006. A área de estudo localiza-se entre as coordenadas geográficas $48^{\circ} 21^{\prime}$ a $48^{\circ}$ $23^{\prime}$ de longitude WGr. e $22^{\circ} 52^{\prime} S$ e $22^{\circ} 56^{\prime}$ de latitude $S$ com uma área de 1458,4 ha. Os resultados permitiram verificar que as técnicas de geoprocessamento foram de importância fundamental na identificação das áreas de uso de terra, de APPs e de conflitos entre uso e APPs onde uma pequena parte das áreas de APPs está conflitando. Em termos de sustentabilidade ambiental, pode ser deduzido que a microbacia é desfavorável, uma vez apresenta com quase $44 \%$ da área usada inadequadamente por pastagens.

Palavras-chave: microbacia, imagem de satélite, uso do solo.

\section{INTRODUÇÃO}

\footnotetext{
${ }^{1}$ Prof. Adjunto, Departamento de Engenharia Rural, Faculdade de Ciências Agronômicas/UNESP. seca@fca.unesp.br.

${ }_{2}^{2}$ Profa. Dra., Departamento de Engenharia Rural, Faculdade de Ciências Agrárias e Veterinárias/UNESP

${ }^{3}$ Discentes do Programa de Pós-Graduação em Agronomia - Energia na Agricultura da Faculdade de Ciências Agronômicas/UNESP. seca@fca.unesp.br
} 


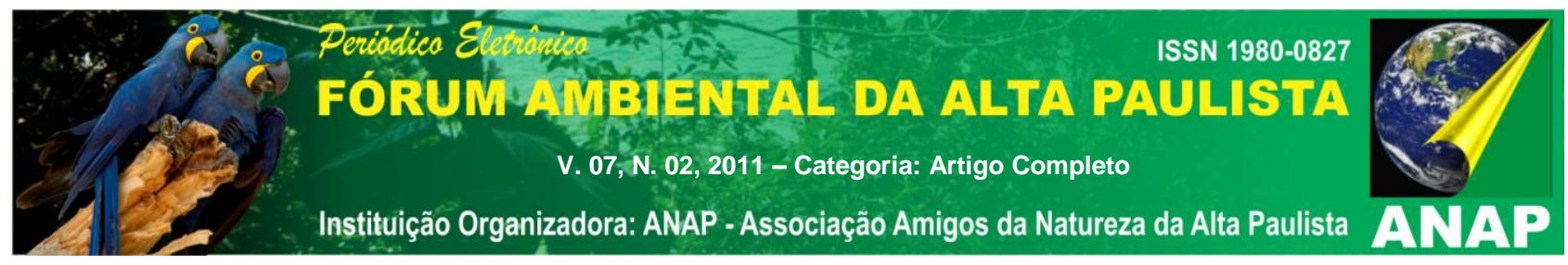

O sensoriamento remoto é a ciência e a arte de se obterem informações sobre um objeto, área ou fenômeno, através da análise de dados coletados por aparelhos denominados sensores, que não entram em contato direto com os alvos em estudo.

A análise do uso e cobertura do solo, mediante informações de Sensoriamento Remoto, constitui uma técnica de grande utilidade ao planejamento e administração da ocupação ordenada e racional do meio físico, além de possibilitar avaliar e monitorar a preservação de áreas de vegetação natural. Através da interpretação de imagens de satélite obtém-se, de forma rápida, um mapa temático atualizado e preciso das diferentes estruturas espaciais resultantes do processo de ocupação e uso do solo (RODRIGUEZ, 2000).

Uma das vantagens de se utilizar o sensoriamento remoto para interpretação do uso da terra é que as informações podem ser atualizadas devido à característica de repetitividade de aquisição das imagens de forma global, confiável, rápida, sendo estes dados de grande importância para o levantamento, mapeamento e utilização das informações de uso e ocupação do solo regional.

O uso inadequado do solo pelo homem é um fator agravante da degradação ambiental e desequilíbrio ecológico. É necessário que a atuação do homem no meio ambiente seja planejada e adequada de modo que os efeitos ao ambiente físico sejam os menores possíveis (MOTA, 1981).

O acompanhamento da dinâmica do uso do solo nos municípios tem grande importância no intuito de refletir sobre as mudanças de aspectos sócio-econômicos de determinadas regiões e até mesmo permitir o seu monitoramento ambiental. Neste contexto, as imagens de satélite constituem-se em importante ferramenta, bem consolidadas, como fonte de dados espaço-temporais permitindo análises das mudanças ocorridas no uso do solo, ou seja, na forma como o espaço está sendo utilizado pelo homem.

Este projeto de pesquisa teve por objetivo analisar a aplicação do geoprocessamento na espacialização das áreas de preservação permanente e de conflitos na microbacia Ribeirão São Pedro - SP, através do uso do Sistema de Informações Geográficas (SIG) e de imagem de satélite.

\section{MATERIAL E MÉTODOS}




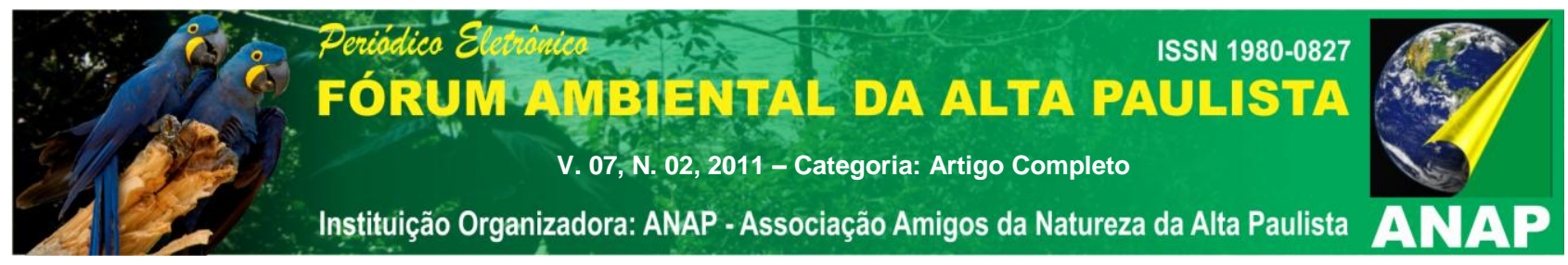

O trabalho foi desenvolvido na microbacia do Ribeirão São Pedro, Botucatu (SP), definido pelas coordenadas geográficas: $48^{\circ} 21^{\prime}$ a $48^{\circ} 23^{\prime}$ de longitude WGr. e $22^{\circ} 52^{\prime} \mathrm{S}$ a $22^{\circ} 56^{\prime}$ de latitude S com uma área de 1458,4ha.

O clima predominante do município, classificado segundo o sistema Köppen é do tipo Cwa - Clima subtropical úmido com invernos secos e verões quentes - em que a temperatura do mês mais frio é inferior a $18^{\circ} \mathrm{C}$ e do mês mais quente ultrapassa os $22^{\circ} \mathrm{C}$.

O relevo da região é bastante acidentado apresentando grande amplitude altimétrica, variando de $440 \mathrm{~m}$ a $620 \mathrm{~m}$.

O contorno da área da microbacia do Ribeirão São Pedro - Botucatu (SP) foi realizado manualmente na Carta Planialtimétrica editada pelo Instituto Brasileiro de Geografia e Estatística - IBGE em 1969, folha de Pratânia (SF-22-R-IV-3), escala 1:50000, segundo os pontos mais elevados em torno da drenagem.

A imagem foi scanerizada e exportada para o software IDRISI Andes para ser georreferenciada e onde foram feitas as composições RGB para cada uma das datas.Posteriormente foi exportada para o softaware CARTALINX onde o limite da bacia foi vetorizado.

No georreferenciamento, foram utilizados dois arquivos de pontos de controle, sendo o primeiro da imagem digital e o outro, da carta topográfica de Botucatu, onde foram determinadas as coordenadas de cada ponto para elaboração de um arquivo de correspondência, através do comando "Edit" do menu "Database Query", presente no módulo "Analysis". Inicialmente, foi elaborada uma composição falsa cor com a combinação das bandas 3, 4 e 5, obtida a partir da imagem de satélite digital, bandas 3, 4 e 5 do sensor "Thematic Mapper" do LANDSAT - 5, da órbita 220, ponto 76, quadrante A, passagem de 23/10/2006, escala 1:50000, pois esta apresenta uma boa discriminação visual dos alvos, possibilitando a identificação dos padrões de uso da terra de maneira lógica. Esta composição apresenta os corpos d'água em tons azulados, as florestas e outras formas de vegetações em tons esverdeados e os solos expostos em tons avermelhados. A seguir, foi realizado o georeferenciamento da composição falsa cor, utilizando-se para isso do módulo Reformat/Resample do SIG - IDRISI Andes.

Após o georreferenciamento, foi feito o corte e a extração da área da microbacia, sendo demarcadas as áreas de treinamento sobre a imagem com o cursor e o mouse. 


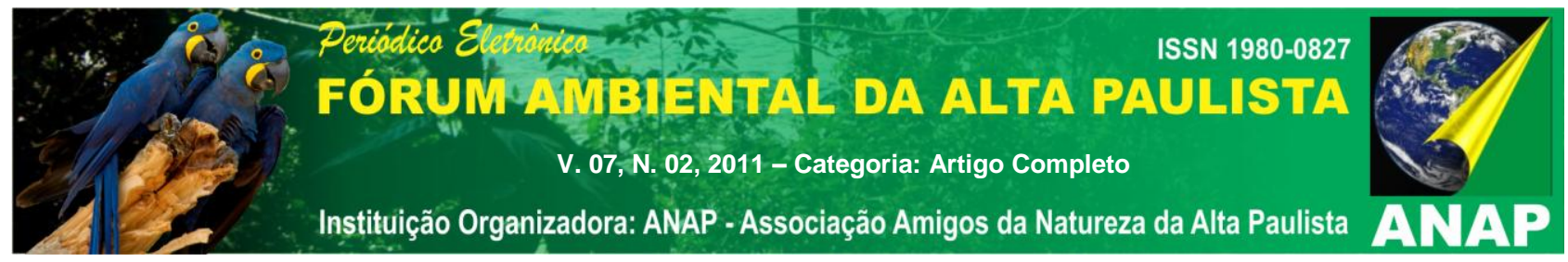

Essas áreas foram demarcadas sobre grande número de locais, buscando-se abranger todas as variações de cada ocupação do solo. Depois, foram criadas as assinaturas pelo módulo Makesig e a classificação supervisionada propriamente dita pelo método de Máxima Verossimilhança, pelo módulo Maxlike.

$\mathrm{Na}$ classificação supervisionada, as ocupações do solo foram identificadas e diferenciadas, umas das outras pelo seu padrão de resposta espectral, sendo as áreas de treinamento delimitadas por polígonos desenhados sobre cada uso da terra na imagem. Em seguida, foram indicados os nomes para cada classe de uso da terra, associados aos seus respectivos identificadores, sendo a imagem classificada e os cartogramas demonstrativos da distribuição espacial de cada uso da terra com base nestes dados.

$\mathrm{Na}$ identificação digital dos alvos, utilizou-se as chaves de interpretação para imagens (Rocha, 1986) na determinação das classes de uso. Após a elaboração da carta de uso da terra, as áreas foram determinadas com o auxílio do software SIG - IDRISI Andes, utilizando-se do comando "Area" do área do menu "Database Query", pertencente ao módulo "Analysis". As áreas de preservação permanentes foram definidas ao longo dos cursos d'água do Ribeirão São Pedro, onde foi utilizada a operação Buffer Selected Features do software ArcView 3.2, a qual proporciou a criação de um buffer de 50m de raio das áreas das nascentes e um buffer de $30 \mathrm{~m}$ de cada lado da drenagem ao longo do leito do córrego, com isso resultando no mapa de APPs, fundamentado na resolução CONAMA n 303/2002, Art. 3: "Constitui Área de Preservação Permanente a área situada em faixa marginal, medida a partir do nível mais alto, em projeção horizontal, com largura mínima de trinta metros, para o curso d'água com menos de 10 metros de largura”, e no Código Florestal (Lei 4.771/1965), que considera essas áreas, cobertas ou não por vegetação nativa: "com a função ambiental de preservar os recursos hídricos, a paisagem, a estabilidade geológica, a biodiversidade, o fluxo gênico da fauna e flora, proteger o solo e assegurar o bem-estar das populações humanas".

O mapeamento e a quantificação dos conflitos de uso da terra em áreas de preservação permanentes foram realizados usando-se álgebra de mapas. Os procedimentos foram executados no ambiente Raster Calculator no módulo Spatial Analyst do ArcGIS.

\section{RESULTADOS E DISCUSSÃO}




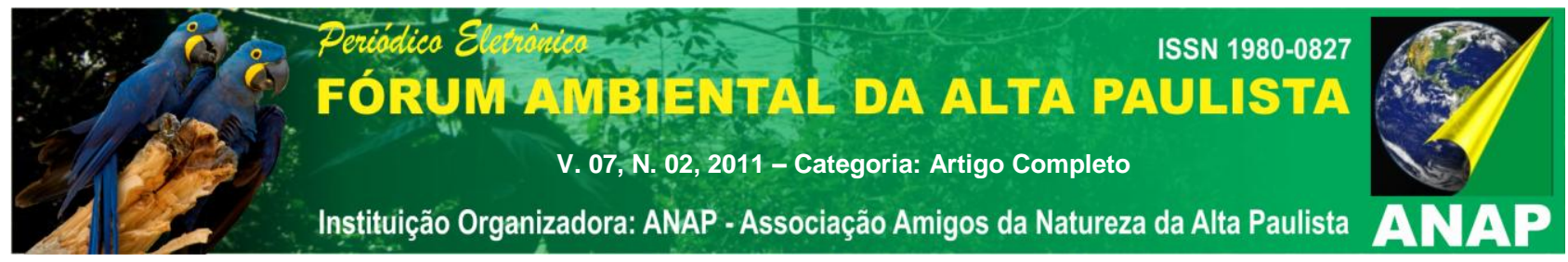

A análise do uso da terra (Figura 1 e Quadro 1) na microbacia do Ribeirão São Pedro - Botucatu (SP) permitiu inferir que as pastagens foram as coberturas vegetais que ocuparam a maior parte da área, representando quase $2 / 3$ (61,96\%), ou seja, cobrem 903,63ha, mostrando com isso a predominância da pecuária regional.

As florestas, elementos importantes na preservação ambiental, representam mais de $16 \%$ da área. Estas classes são formadas praticamente por matas ciliares. As matas ciliares são formações florestais que acompanham os rios de pequeno porte e são corredores fechados sobre a rede de drenagem. A mata de galeria protege o solo contra 0 impacto direto das gotas das chuvas, diminuindo a velocidade de escoamento superficial e favorecendo a infiltração de água no solo (Silveira et al., 2005).

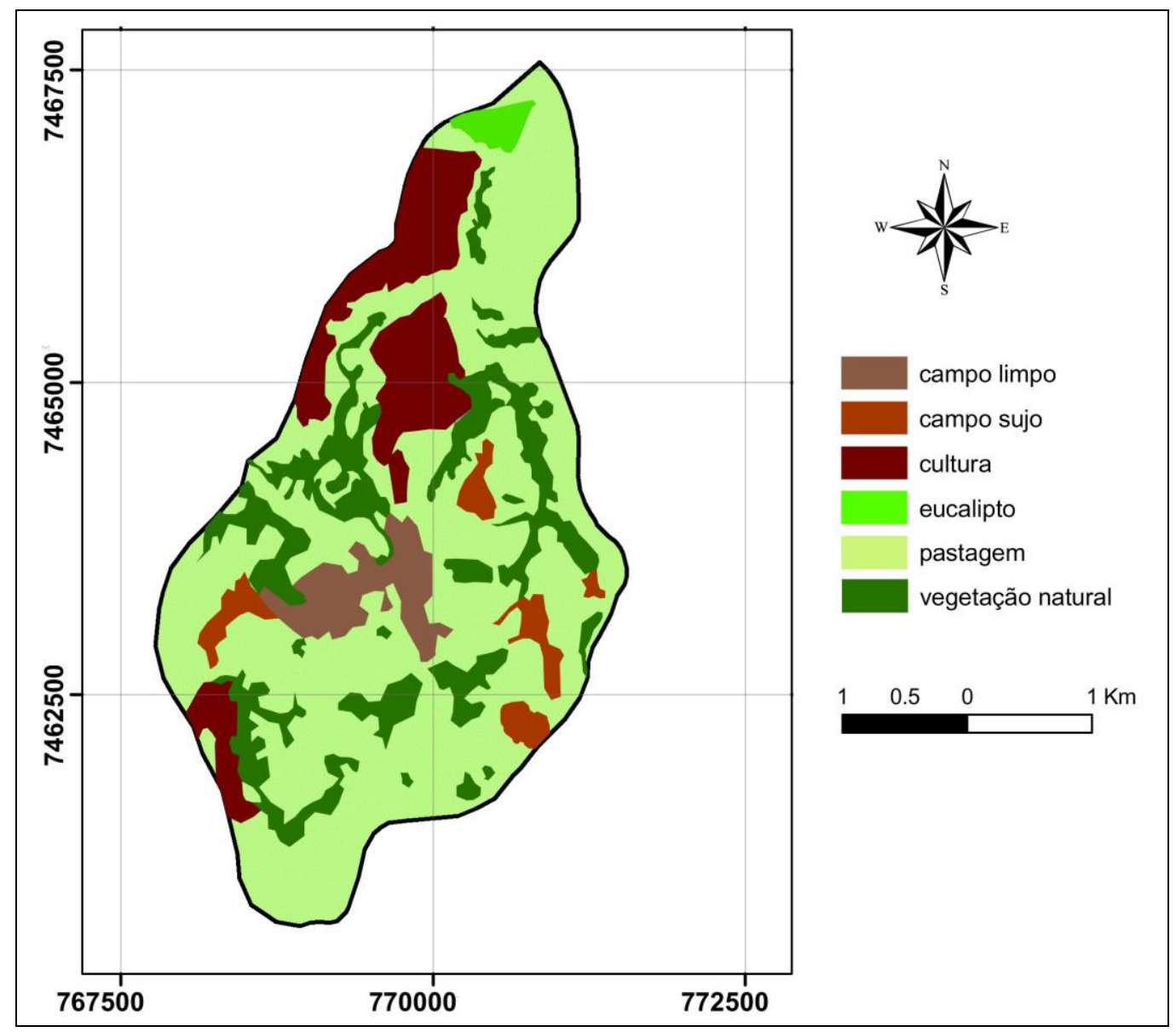

Figura 1. Uso do solo da microbacia do Ribeirão São Pedro - Botucatu - SP.

Quadro 1. Uso do solo da microbacia do Ribeirão São Pedro - Botucatu - SP.. 


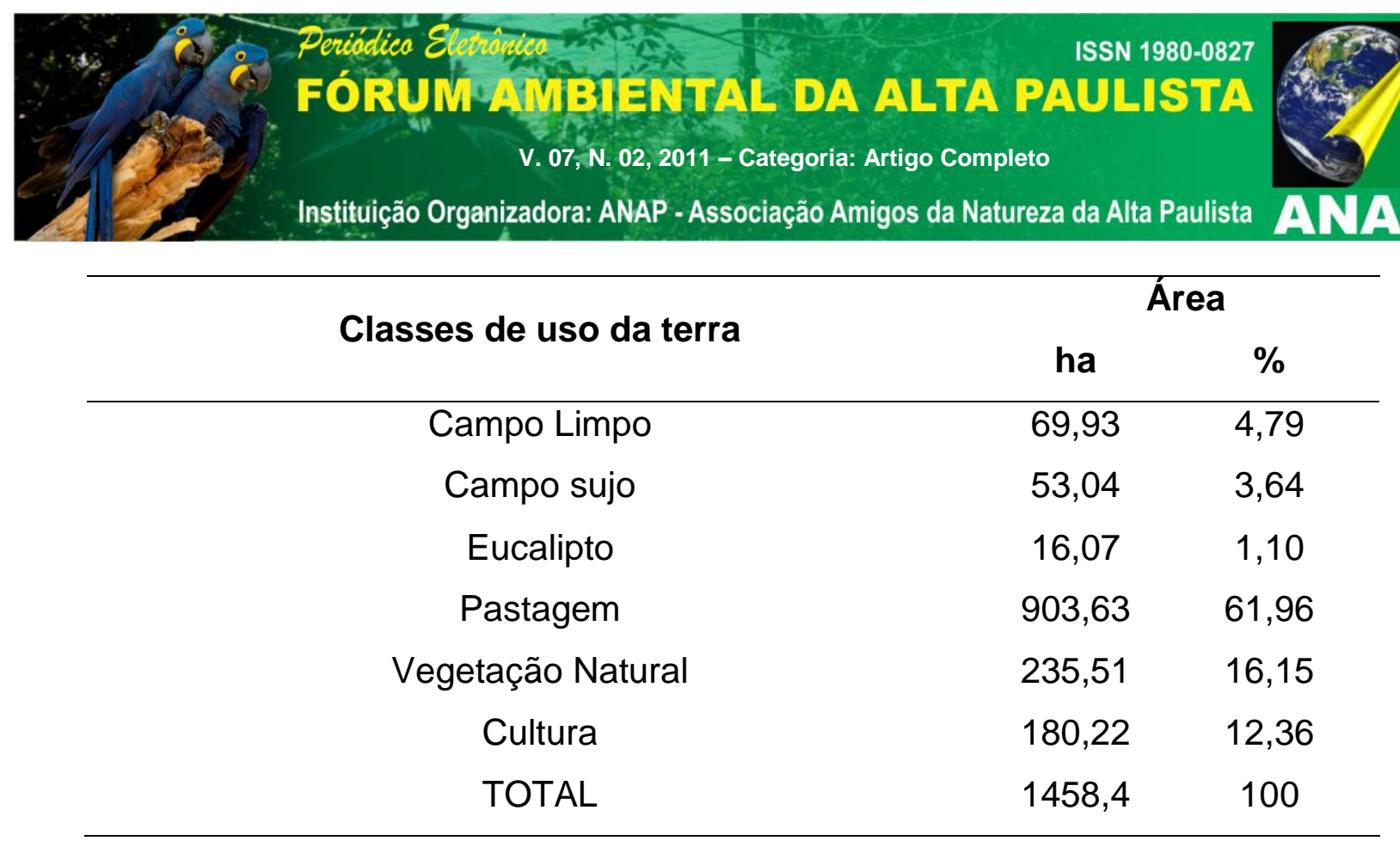

Os 84,64ha de áreas de APPs (Figura 2 e Quadro 2) ao longo da rede de drenagem estão ocupados com reflorestamento $(0,12 \%)$ e pastagem $(43,87 \%)$ de forma inadequada (conflito) . Portanto, 43,99\% da área de APP vêm sendo utilizados adequadamente, enquanto que 56,01\% vem sendo utilizado inadequadamente (conflitos), principalmente com pastagens $(99,73 \%)$, demonstrando que a microbacia está parcialmente conservada ambientalmente segundo o Código Florestal Brasileiro vigente (1965). 

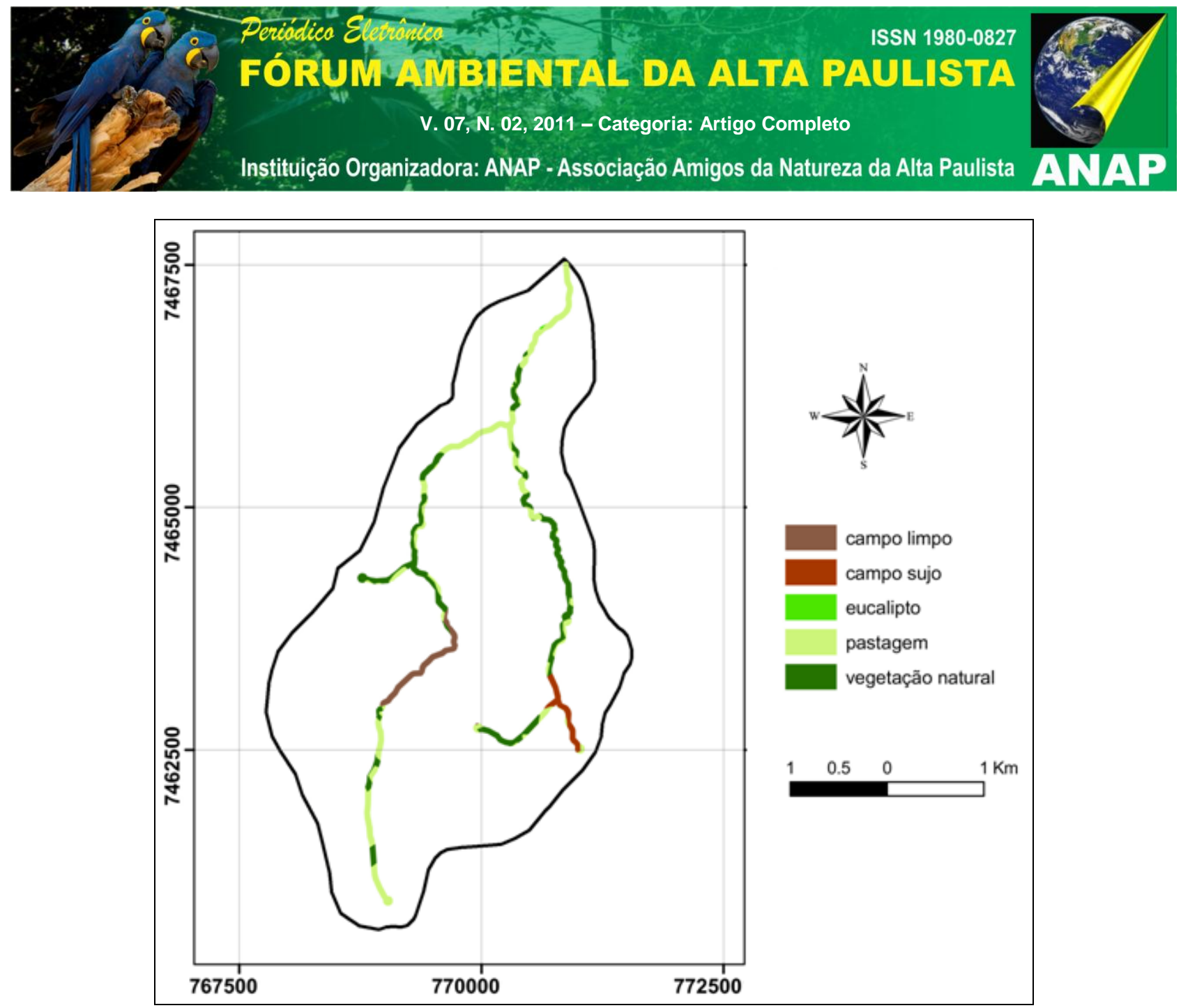

Figura 2. Conflito de uso do solo em APPs da microbacia do Ribeirão São Pedro Botucatu - SP.

Quadro 2. Uso do solo e conflito de uso em APP's da microbacia do Ribeirão São Pedro - Botucatu - SP.

\begin{tabular}{cccccc}
\hline & \multicolumn{3}{c}{ Área } \\
Classes de uso da terra & \multicolumn{2}{c}{ APP } & \multicolumn{3}{c}{ Conflito } \\
& ha & $\%$ & ha & $\%$ \\
\hline Campo Limpo & 7,97 & 9,41 & & \\
Campo sujo & 5,64 & 6,67 & & \\
Eucalipto & 0,10 & 0,12 & 0,10 & 0,27 \\
Pastagem & 37,13 & 43,87 & 37,13 & 99,73 \\
Vegetação Natural & 33,80 & 39,93 & & \\
Total & 84,64 & & 37,23 & 100 \\
\hline
\end{tabular}




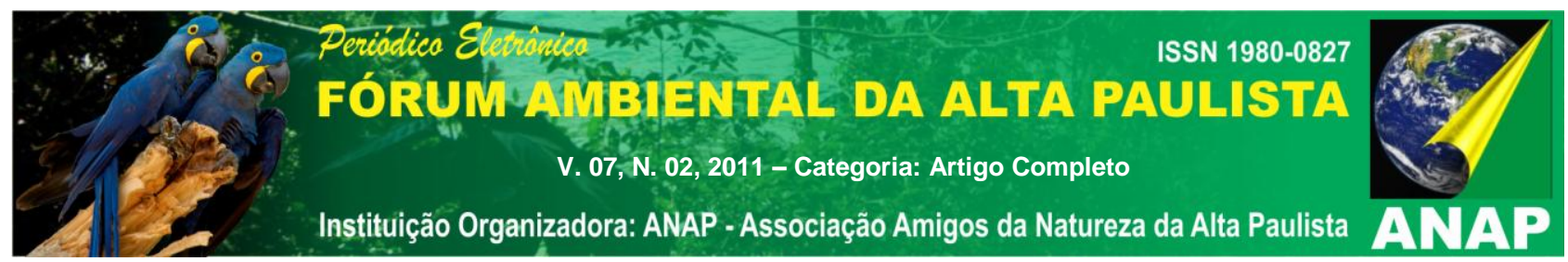

\section{CONCLUSÕES}

O Sistema de Informações Geográficas - Arc View 3.2 foi eficiente na discriminação e avaliação das classes de uso do solo. As florestas (Campo limpo e sujo e vegetação natural) representando 56,01\% mostram que o uso inadequado das áreas de preservação permanente por pastagens chega a quase 100\%. Os mapas de uso da terra podem servir como poder de fiscalização futuramente pelos Órgãos Públicos, bem como para identificação e localização das áreas de conflitos de uso da terra. O uso de técnicas de sensoriamento remoto através do emprego de produtos orbitais do Landsat mostrou-se eficientes na definição do uso do solo e na integração dos dados georreferenciados dentro de um banco de dados, pois mostra ser uma ferramenta fundamental para 0 planejamento de uso do solo numa microbacia, bem como a sua utilização no atendimento à legislação ambiental, principalmente nas áreas de APPs.

\section{AGRADECIMENTOS}

Os autores agradecem ao CONSELHO NACIONAL DE DESENVOLVIMENTO CIENTífICO E TECNOLÓGICO - CNPQ pelo apoio financeiro, sem o qual não seria possível a apresentação deste trabalho no evento.

\section{REFERÊNCIAS}

BRASIL. Lei $n^{\circ}$ 4.771, de 15 de Setembro de 1965, que institui o novo Código Florestal. MOTA, S. Planejamento urbano e preservação ambiental. Fortaleza, Edições UFC, $1981.242 \mathrm{p}$.

ROCHA, J.S.M. da. Manual de interpretação de aerofotogramas, Fascículo XI, Santa Maria, 1986, 58p.

RODRIGUEZ, A. C. M. Mapeamento multitemporal do uso e cobertura do solo do município de São Sebastião-SP, utilizando técnicas de segmentação e classificação de imagens TM-Landsat e HRV-SPOT. São José dos Campos: INPE, 94p. 2000. (INPE - 7510 - PUD/39). 